\title{
THE MAP ROOM
}

\section{Meteorological Conditions Conducive to the Rapid Spread of the Deadly Wildfire in Eastern Attica, Greece}

\author{
K. Lagouvardos, V. Kotroni, T. M. Giannaros, and S. Dafis
}

$E^{x}$ xtreme fire behavior is a term extensively used in the literature with various subjective definitions. Werth et al. (2016) came up with the following definition of extreme fire behavior: "fire spread other than steady surface spread, especially when it involves rapid increases"; they also stated that all three factors of the fire behavior triangle-fuels, weather, and topography-should be taken into account when framing perceptions of extreme fire behavior. Focusing on the weather conditions contributing to extreme fire behavior, Werth et al. (2016) in their review of previous studies identified four such elements: low relative humidity, strong surface wind, unstable air, and drought. Strong surface winds, high temperatures, and low relative humidity develop during strong downslope winds (Whiteman 2000; Huang et al. 2009; Mass and Ovens 2019). Such conditions occur particularly often in the Mediterranean-type ecosystem of Southern California, where wildfires are clearly associated with strong downslope winds (Abatzoglou et al. 2013; Nauslar et al.

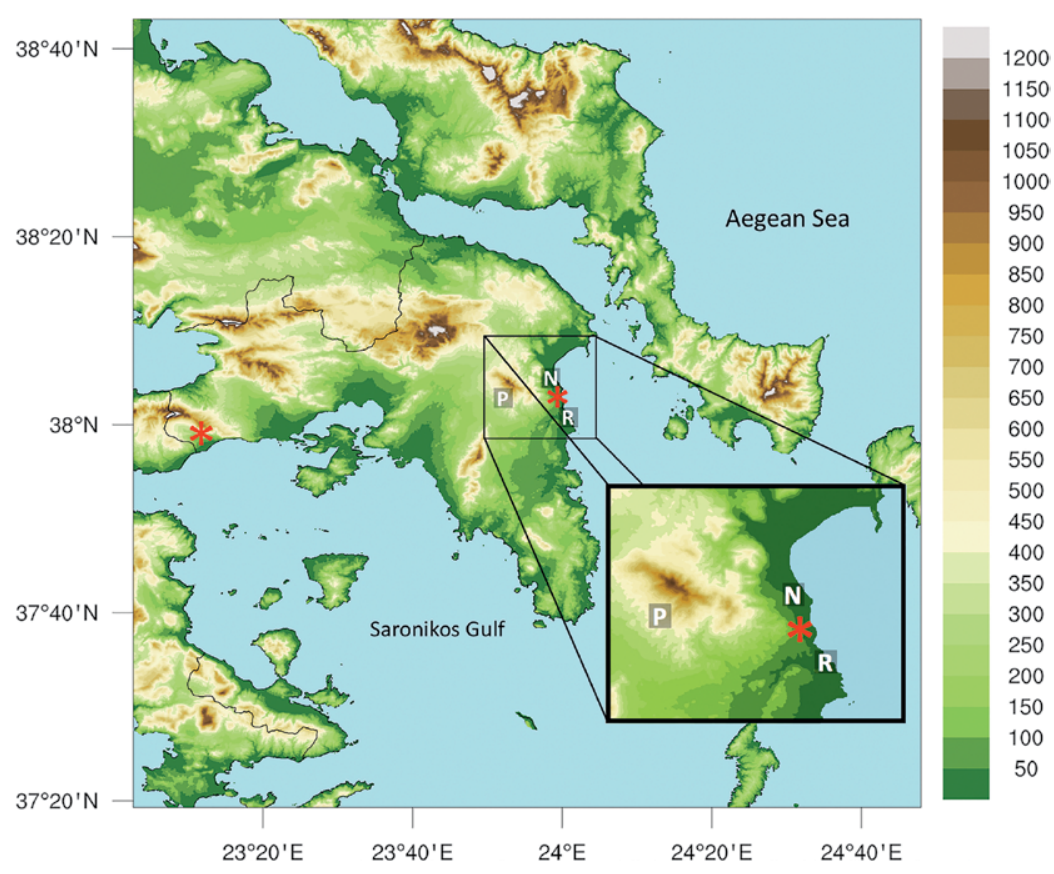

FIG. I. Map of the Attica region. The red asterisks denote the starting points of the two forest fires. Letters $\mathbf{P}, \mathbf{R}$, and $\mathbf{N}$ denote the locations of the Penteli, Rafina, and Nea Makri automatic weather stations, respectively. Shading depicts the model-resolved topography (at 50-m intervals). A zoom over the area of interest is also provided as an inset map.
AfFiliations: Lagouvardos, Kotroni, Giannaros, and DafisNational Observatory of Athens, Athens, Greece CORRESPONDING AUTHOR: Konstantinos Lagouvardos, lagouvar@noa.gr

The abstract for this article can be found in this issue, following the table of contents.
2018; Mass and Ovens 2019). In the western Mediterranean, large summer wildfires were also found to be 

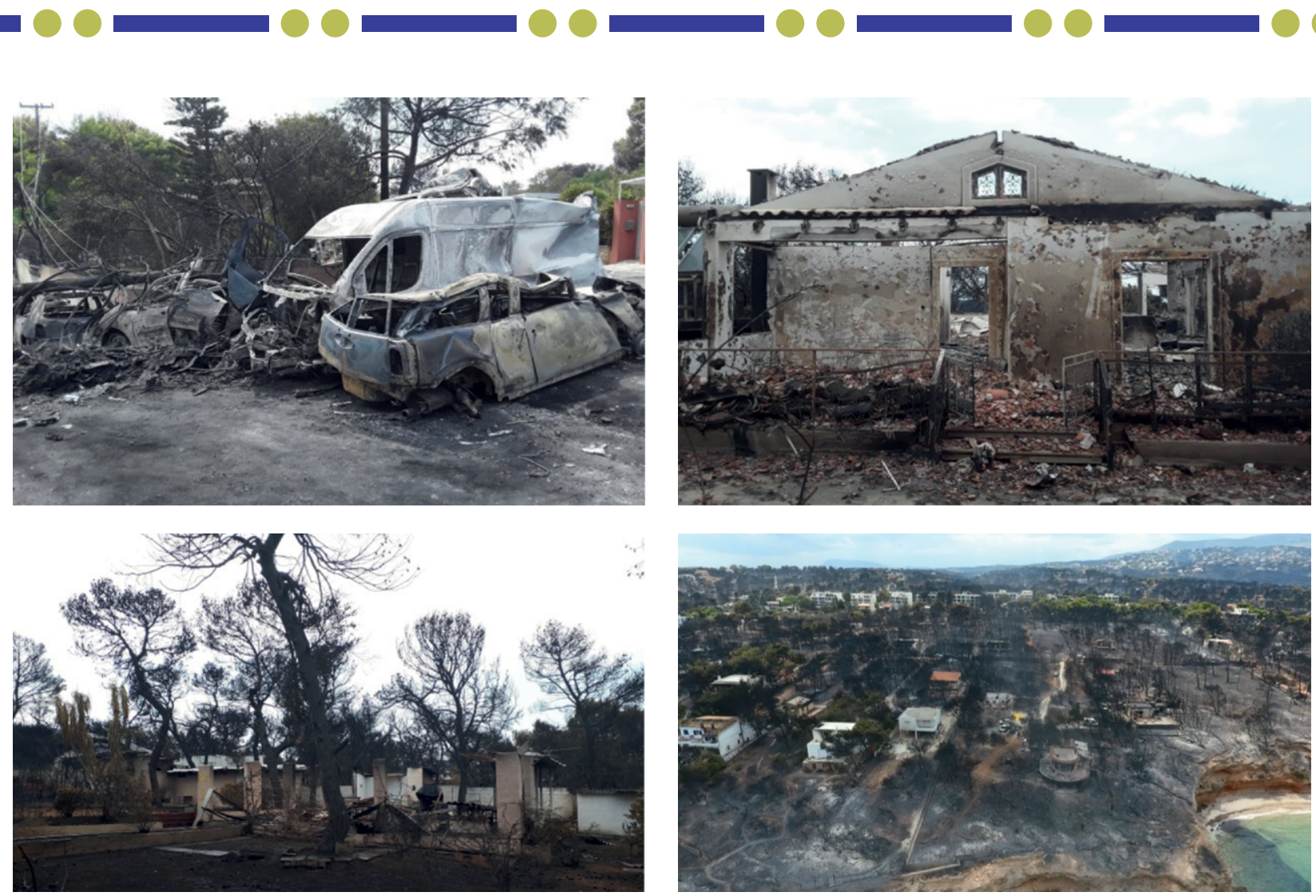

Fig. 2. Vehicles and houses burned within Mati area. (bottom-right) An aerial view of part of the coastline. The photos were taken 2 days after the disaster. (SOURCE: Lekkas et al. 2018)

associated with strong continental dry winds (Ruffault et al. 2017). In the eastern Mediterranean, and more precisely in Greece, Diakakis et al. (2016), who studied forest-fire-related fatalities for a 36-yr period, found that major events were related to high temperatures (over $30^{\circ} \mathrm{C}$ ), low relative humidity (less than $30 \%$ ), and wind speeds exceeding $8 \mathrm{~m} \mathrm{~s}^{-1}$.

The motivation of the present study is the recent deadly wildfire that took place in Attica, Greece, on 23 July 2018. At around 0900 UTC, a wildfire was ignited in a dense pine forest in the western part of Attica, spreading rapidly, but fortunately did not result in any human casualties. Almost $5 \mathrm{~h}$ later, at 1355 UTC, a wildfire broke out in a mountainous forested area of the east of Attica (see Fig. 1 for the location of the areas mentioned in the text). The rapid spread of the second wildfire toward the east affected a wildland-urban interface (WUI) area and resulted in the death of 102 civilians in less than $3 \mathrm{~h}$. The exceptionally high death toll establishes this event as the second-deadliest weather-related disaster in Greece, the major heat wave of July 1987 being the deadliest. Apart from the human casualties, the destruction included approximately 3,000 houses partially or totally burned and 305 burned vehicles, while the total area burned reached 1,250 ha (Lekkas et al. 2018). A series of photos depicting the catastrophic impact of the wildland fire are shown in Fig. 2.

The rest of the paper is structured as follows. First the prevailing meteorological conditions during the event are briefly discussed, based on the combined analysis of automatic weather station (AWS) observations, provided by the National Observatory of Athens (NOAAN; Lagouvardos et al. 2017), and model results from high-resolution simulations carried out with a coupled fire-atmosphere modeling system. Then the results of the fire spread simulations are presented. Finally, the main findings are summarized and the key points related to improving preparedness are discussed, especially with respect to wildfires taking place in the WUI.

\section{BRIEF SYNOPTIC DESCRIPTION AND SURFACE OBSERVATIONS. The $0.25^{\circ}$-hori-} zontal-resolution Global Data Assimilation System (GDAS) tropospheric analyses data were employed for the examination of the synoptic setup during the event (Fig. 3). Regional- to local-scale conditions, related to 


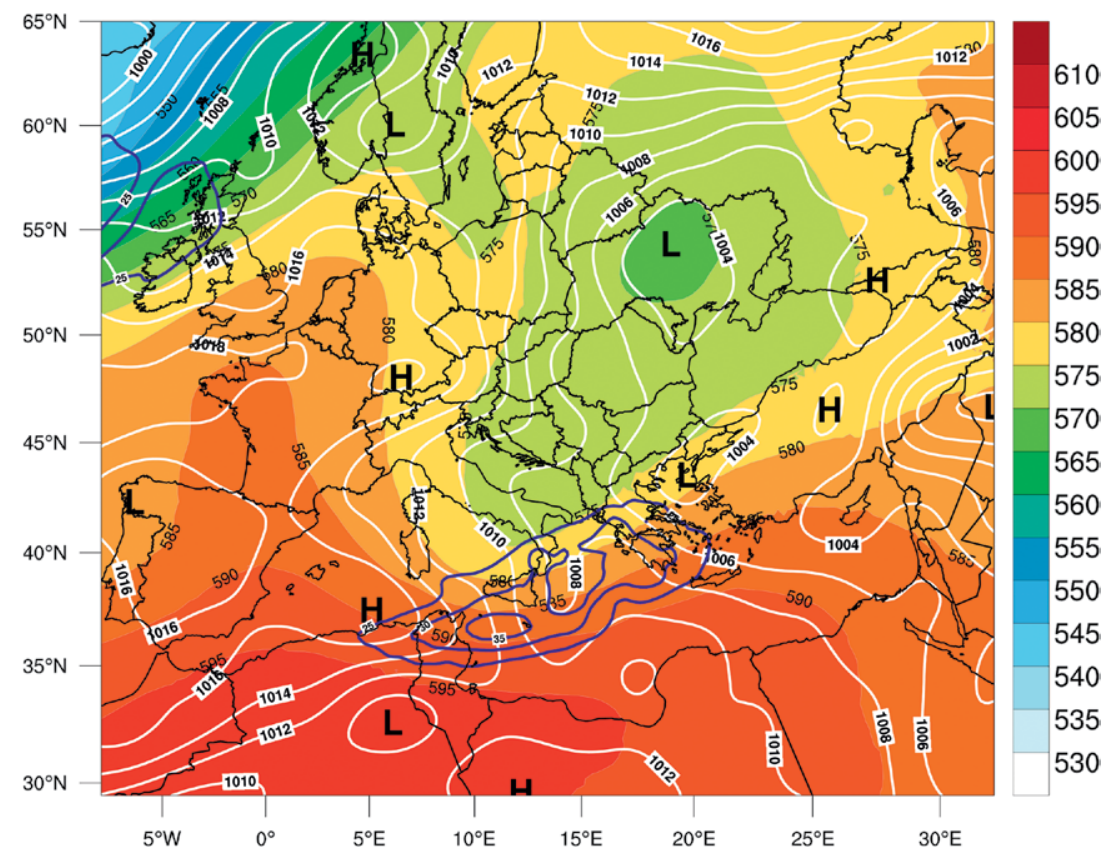

FIG. 3. GDAS analysis of 500-hPa geopotential height (shading at 50-gpdm intervals), mean sea level pressure (white contours at 2-hPa intervals), and wind speed at $500 \mathrm{hPa}$ (blue contours between 25 and $35 \mathrm{~m} \mathrm{~s}^{-1}$ at $5 \mathrm{~m} \mathrm{~s}^{-1}$ intervals) valid at I200 UTC 23 Jul 2018.

the development of downslope winds in the study area, were analyzed based on model simulations.

The upper-level flow between 0000 and 1200 UTC 23 July 2018 was characterized by a positively tilted trough over the central Mediterranean, moving eastward and interacting with an intensifying subtropical ridge downstream (Fig. 3). The net result of this convergence was a subtropical jet stream extending from southern Italy toward Greece, with a $25-35 \mathrm{~m} \mathrm{~s}^{-1}$ jet streak at $500 \mathrm{hPa}$ (Fig. 3, blue contours) and $20-25 \mathrm{~m} \mathrm{~s}^{-1}$ at $850 \mathrm{hPa}$ (not shown). At the surface, a 1,003-hPa low pressure system in the north Aegean Sea at 1200 UTC (Fig. 3, white contours) was further deepening, enhancing the strong westerly flow over most of Greece. At this point it is worth mentioning that the typical high-wind regime over the Aegean Sea that also affects Attica during summer is the Etesians, which are north sector winds (Kotroni et al. 2001).

Figure 4 shows the 10-min records of mean and maximum wind speed at the Penteli AWS. The station, denoted by the letter $\mathrm{P}$ in Fig. 1, is located at an altitude of $495 \mathrm{~m}$ and is $7 \mathrm{~km}$ west of the ignition point. Two distinct periods of high winds are evident. The first period, with mean wind speed exceeding $15-16 \mathrm{~m} \mathrm{~s}^{-1}$ and gusts reaching $25 \mathrm{~m} \mathrm{~s}^{-1}$, was observed between 1230 and 1430 UTC, a 2-h window that included the time of the fire ignition (1350 UTC). Then, between 1440 and 1520 UTC, the wind speed decreased to $\sim 10 \mathrm{~m} \mathrm{~s}^{-1}$, while the second 2-h period of high winds started right after, with mean wind speed and gusts peaking at 18 and $26 \mathrm{~m} \mathrm{~s}^{-1}$, respectively. During this last time window, the wildfire spread toward the sea. It should be noted that the wind gusts recorded during this day at many stations were the highest recorded since 2010 (when the AWS

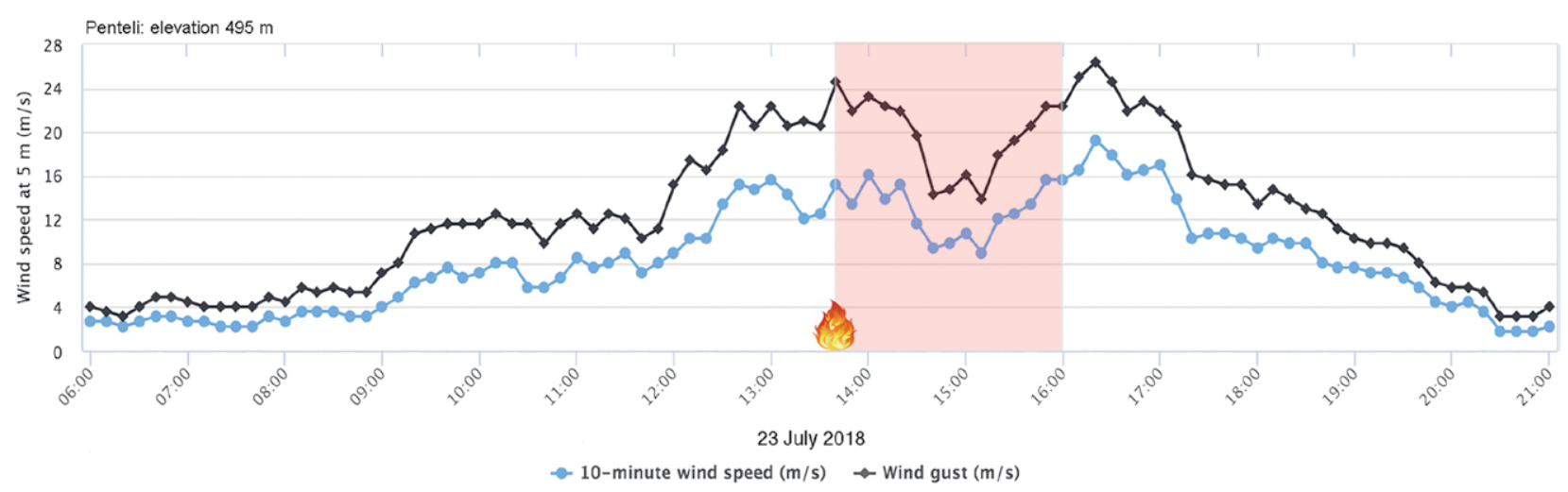

FIG. 4. Temporal evolution of wind speed (mean and gusts) at Penteli AWS between 0600 and 2100 UTC 23 Jul $2018\left(\mathrm{~m} \mathrm{~s}^{-1}\right.$; at 10-min intervals). The time of the fire ignition is denoted with the flame while the duration of the fire event is shaded. 


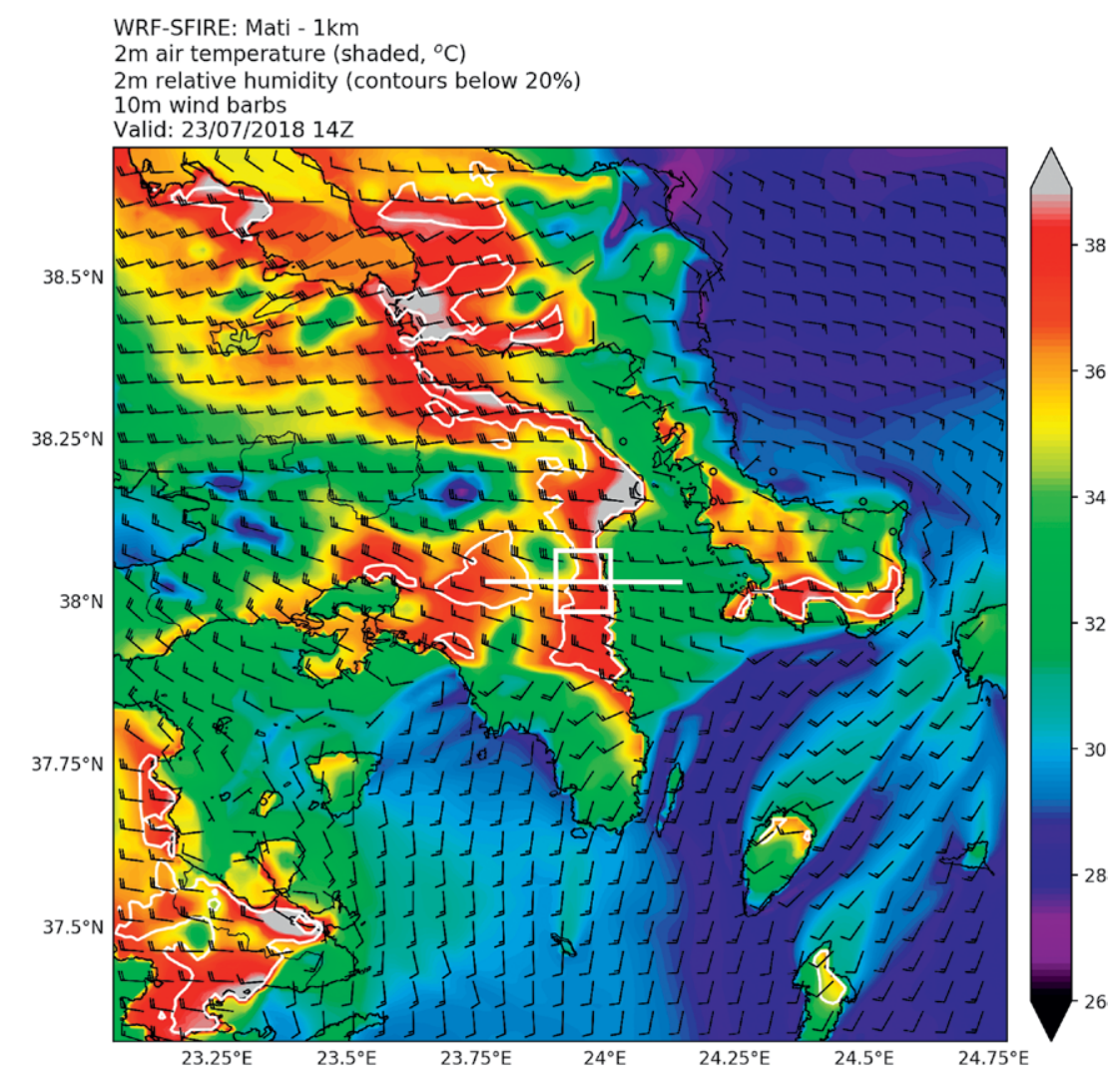

FIG. 5. WRF-SFIRE simulated fields at I-km grid increment, valid at I400 UTC 23 Jul 20 I8: 2-m temperature (color shading, following the color bar shown on the right), $2-\mathrm{m}$ relative humidity below $20 \%$ (within the white contour line), and $10-\mathrm{m}$ sustained wind speed (wind barbs; one barb equals $5 \mathrm{~m} \mathrm{~s}^{-1}$, one half-barb equals $2.5 \mathrm{~m} \mathrm{~s}^{-1}$ ). The white line denotes the location of the cross section shown in Fig. 6, and the white box denotes the part of WRF-SFIRE inner domain that is shown in Figs. 8 and 9.

network NOAAN started to expand in Attica) during any summer month (June-August).

To draw a more detailed picture of the weather situation during the event, the WRF-SFIRE modeling system (Mandel et al. 2011) was employed. WRF-SFIRE is a coupled fire-atmosphere modeling system that combines the Weather Research and Forecasting (WRF) numerical weather prediction model (Skamarock et al. 2008) with a two-dimensional fire spread model (SFIRE; Mandel et al. 2009). For the purposes of this study, WRF-SFIRE was configured with three one-way nested modeling domains $(25,5$, and $1 \mathrm{~km})$, telescopically nested and centered around the location of fire ignition. The 0600 UTC forecast cycle of the Global Forecasting System (GFS), available at the time of ignition, was employed for initializing the modeling system at 1200 UTC 23 July 2019, and the model was allowed to integrate until 0600 UTC 24 July 2018. For this part of the study, we only focus on the output of the atmosphere component of WRF-SFIRE at the highest resolution domain (i.e., $1 \mathrm{~km})$.

The simulated temperature over the central and eastern part of Attica, at $1400 \mathrm{UTC}$, ranged between $34^{\circ}$ and $36^{\circ} \mathrm{C}$, while it reached $38^{\circ}-39^{\circ} \mathrm{C}$ in a narrow zone along the eastern coast of Attica (Fig. 5). This is in agreement with observations from the Rafina and Nea Makri AWS (denoted by letters $\mathrm{R}$ and $\mathrm{N}$ in Fig. 1, respectively), where such high temperatures were recorded. The maximum daily temperature recorded at Rafina AWS during 23 July 2019 was $39^{\circ} \mathrm{C}$ (at 1230 UTC) and this was the highest temperature recorded in Attica not only during that day, but also during all summer months of 2018.

The narrow band along the eastern coasts of Attica where temperature exceeded $38^{\circ} \mathrm{C}$ was also very dry with relative humidity (RH) less than 20\% (Fig. 5). Again, the model is consistent with observations, as the Rafina AWS recorded a minimum $\mathrm{RH}$ of $19 \%$ at 1230 UTC and RH remained below $30 \%$ for 10 consecutive hours (from 0950 to 1940 UTC). Finally, the model adequately reproduced the wind field, showing sustained WNW winds around $15-16 \mathrm{~m} \mathrm{~s}^{-1}$ over the area of the wildfire (denoted by the rectangle in Fig. 5). The model results shown in Fig. 5 clearly highlight the occurrence of the combination of high temperature, low relative humidity, and almost gale-force winds, conditions that set the stage for the rapid spread of the wildfire.

A west-east cross section, following the thick line depicted in Fig. 5, is shown in Fig. 6. The cross section was drawn over the southern flanks of Mt. Penteli and crosses the ignition point as well as the Mati area to the east. At 1400 UTC 23 July, the wind vectors within the cross section depict the downslope winds toward the coast. Vertical velocity associated with this downslope flow was about $-2.5 \mathrm{~m} \mathrm{~s}^{-1}$ over the eastern part of the slope. The relative humidity distribution across the cross section shows the drying of the 


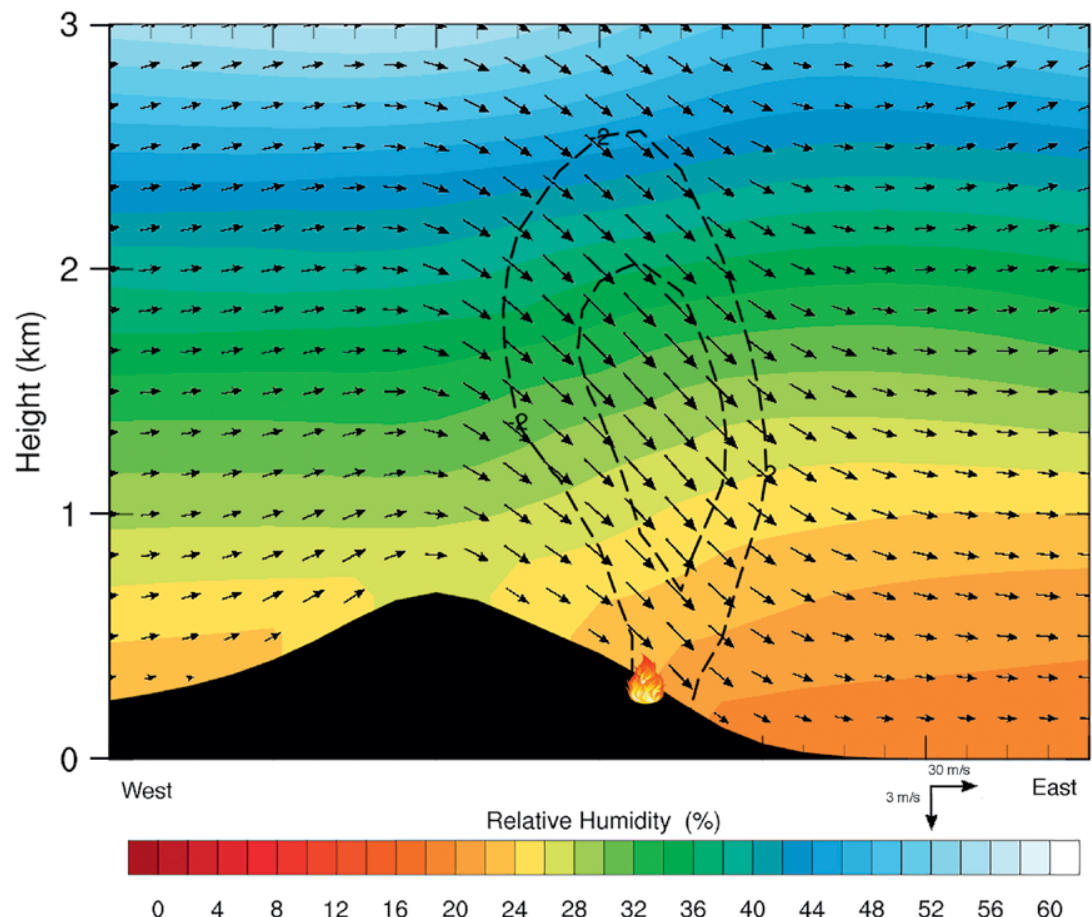

Fig. 6. Vertical cross section valid at 1400 UTC 23 Jul 2018, following the white line shown in Fig. 5, of relative humidity (color shading, following the color bar at the bottom), wind vectors within the cross section (scaled according to the vectors shown at the bottom right), and vertical velocity (dashed lines; only the -2.0 and $-2.5 \mathrm{~m} \mathrm{~s}^{-1}$ contour lines are shown).

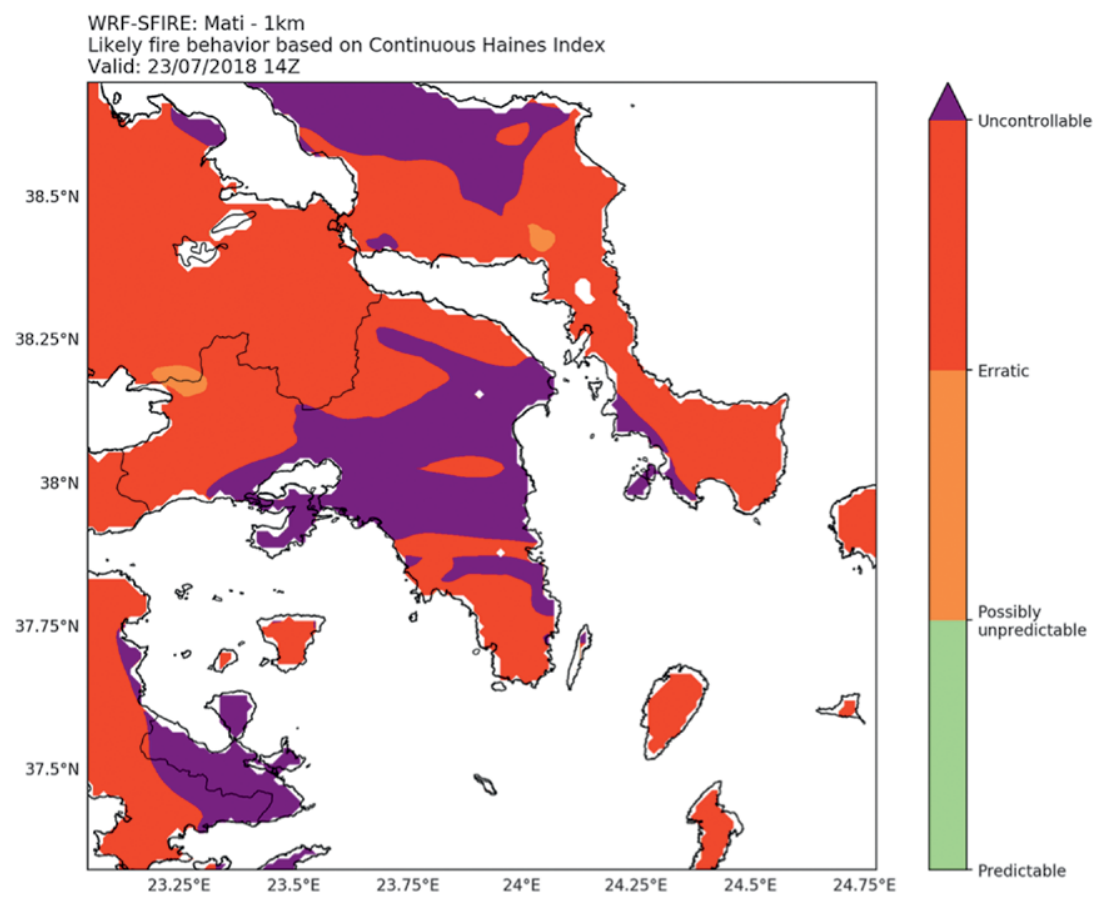

FIG. 7. WRF-SFIRE simulated continuous Haines index at I-km grid increment, valid at 1400 UTC 23 Jul 2018. boundary layer, with RH less than $25 \%$ within the first kilometer of the troposphere and downstream of the mountain.

Last, Fig. 7 presents the modelsimulated continuous Haines index (CHI; Mills and McCaw 2010) at 1400 UTC. CHI values provide a measure of atmospheric stability, indicating conditions that are favorable for the occurrence of extreme fire behavior. The highest $\mathrm{CHI}$ values, suggesting potential for uncontrollable fire behavior, were simulated to coincide spatially (Fig. 7) with the narrow band of high temperature and low humidity along the eastern coasts of Attica (Fig. 5).

FIRE SPREAD SIMULATIONS. Within the framework of WRF-SFIRE, fire spread is simulated with the semiempirical algorithm of Rothermel (1972), which employs the properties of the burning fuels along with terrain (slope) and meteorological data for computing the rate of spread (ROS). The coupling between the fire (SFIRE) and the atmosphere (WRF) occurs primarily through the sensible and latent heat fluxes released by the fire. For a detailed description of WRF-SFIRE, please refer to Mandel et al. (2011, 2014).

WRF-SFIRE was configured with three one-way nested domains (25-, 5-, and 1-km grid increments). The fire spread simulation was carried out in a "fire" domain with grid spacing of $100 \mathrm{~m}$, embedded within the highest-resolution "atmosphere" domain (i.e., $1 \mathrm{~km}$ ). Fuels were represented with 15 standard fuel models derived from Scott and Burgan (2005) and additional custom fuel models based on the description of the eastern Mediterranean ecosystem (Dimitrakopoulos 


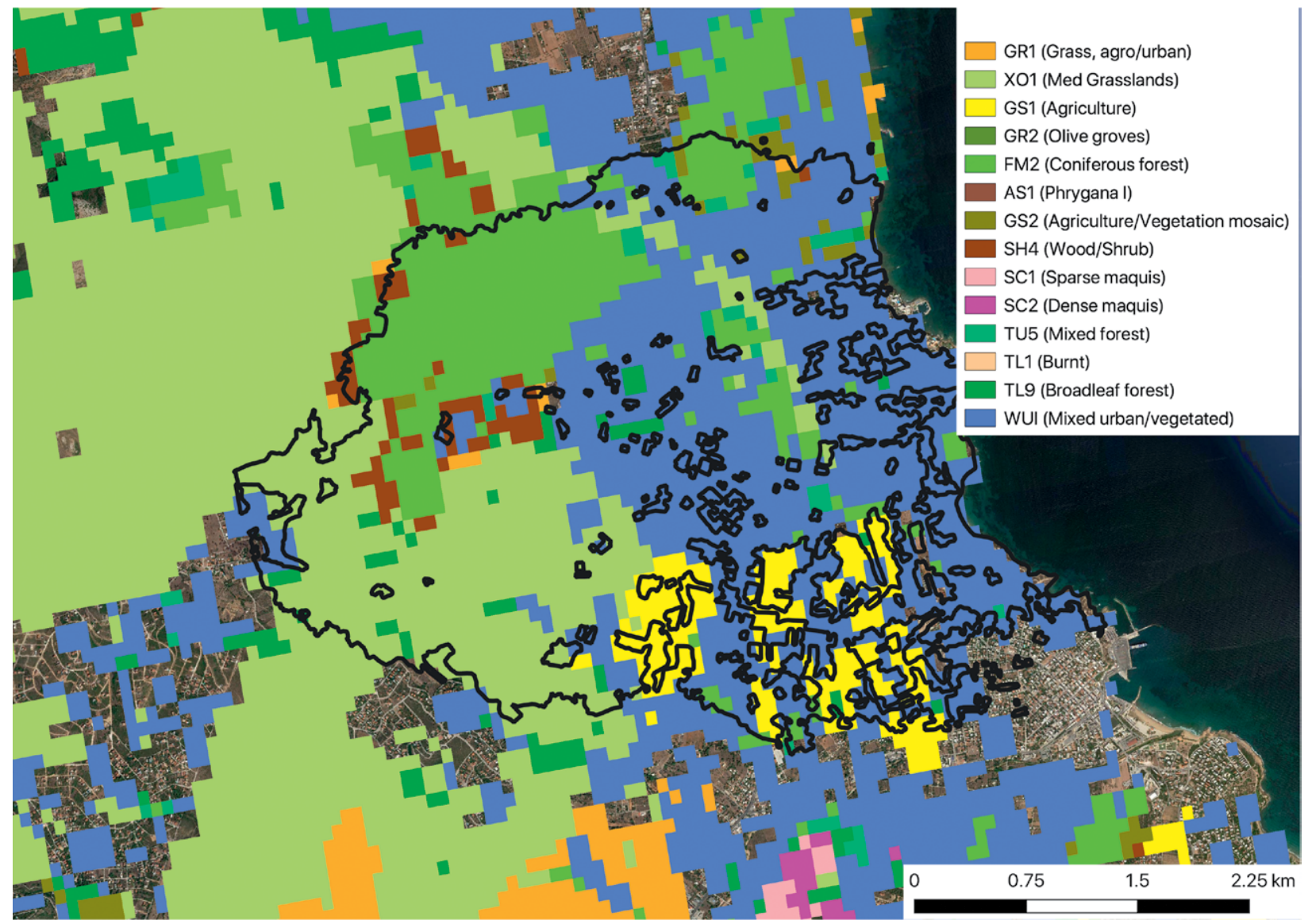

FIG. 8. Fuel models used by the WRF-SFIRE model.

2002; Kalabokidis et al. 2013; Salis et al. 2016) that were selected following several test simulations. The mapping of the selected fuel models was conducted using high-resolution geospatial datasets of the Copernicus Land Monitoring Service (CLMS; https://land .copernicus.eu). Specifically, the datasets used include the 100-m-resolution layers for forests (https://land .copernicus.eu/pan-european/high-resolution-layers /forests) and grasslands (https://land.copernicus .eu/pan-european/high-resolution-layers/grassland), and Coordinate Information on the Environment (CORINE) land cover (https://land.copernicus.eu /pan-european/corine-land-cover). The forests dataset was exploited for defining fuel models for the various forest types (i.e., conifer, broadleaf, and mixed forests), while the grasslands dataset was used for delineating fuel models related to Mediterranean grasslands. Other fuel models (e.g., shrublands, agricultural) were defined by remapping from the CORINE land-cover dataset. In particular, the suburban land-cover categories were combined with tree-cover density data for deriving the WUI fuel model. It should be noted that the use of the CORINE land-cover dataset was of paramount importance for the correct representation of the WUI on WRF-SFIRE simulation process. Test simulations without the use of CORINE dataset failed to correctly advance the fire front within the WUI, which covers a large fraction of the domain. Figure 8 shows the final fuel models' map for the study area.

Figure 9 depicts the fire perimeter and midflame winds at 1500 and 2100 UTC from the WRF-SFIRE simulation while the complete evolution of the simulated wildfire is available in the online supplement. One hour following the ignition of the fire (Fig. 9a), the model simulation indicates a strong westerly flow (velocities up to 8-10 $\mathrm{m} \mathrm{s}^{-1}$ ) that was consistent with concurrent observations (note that the presented wind field refers to the so-called midflame height). More importantly, the simulated fire perimeter indicates that the model was able to reproduce the rapid fire spread. According to news reports and local evidence (Lekkas et al. 2018), the actual fire front reached Marathon Avenue (shown with the 
(a) WRF-SFIRE: Mati - 100m

(a) Fire front position (contour) Wind barbs

Valid: $23 / 07 / 2018$ 15:00Z

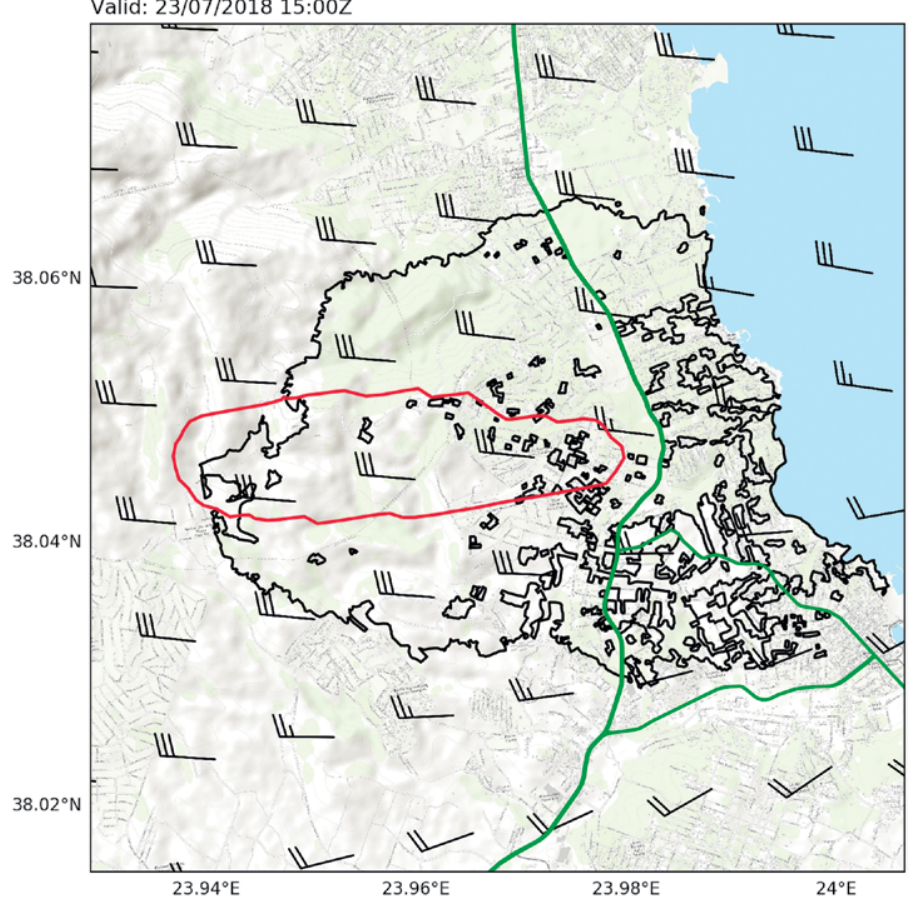

(b) WRF-SFIRE: Mati - $100 \mathrm{~m}$

Fire front position (contour)

Wind barbs

Valid: $23 / 07 / 2018$ 21:00Z

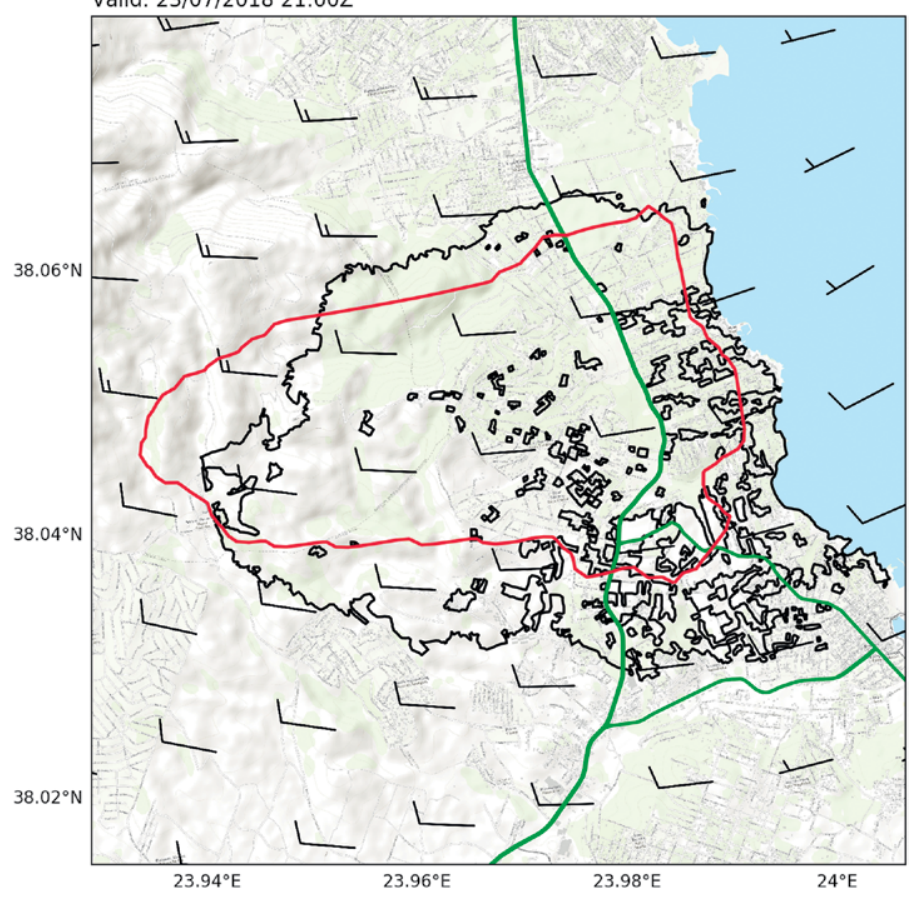

Fig. 9. Fire spread (red contour) simulated by WRF-SFIRE at (a) 1500 and (b) 2100 UTC 23 Jul 2018. The thick black line denotes the fire scar as defined by satellite data analysis. The green lines are used to delineate major roads in the study area. WRF-SFIRE $10-\mathrm{m}$ wind speed at a I-km grid increment is also shown. north-south-oriented green line in Fig. 9) approximately $1 \mathrm{~h}$ following ignition that was timely reproduced by the model (Fig. 9a). By 2100 UTC (Fig. 9b) the simulated fire had already spread across most of its actual final perimeter. Further, the simulated total area burned (1,659 ha) was in good agreement with observations (1,276 ha). The currently available computing infrastructure permits the timely execution of such rapid response fire spread forecasting systems. More specifically, the fire spread simulation of $6 \mathrm{~h}(24 \mathrm{~h})$, with the setup of the current work, takes $15 \mathrm{~min}$ ( $1 \mathrm{~h}$ ) clock time, using 200 cores of the computing infrastructure of the National Observatory of Athens. Thus, it is evident that WRF-SFIRE could be used for providing a fire spread forecast guidance.

CONCLUDING REMARKS. The deadly wildfire that affected Attica on 23 July 2018 was a typical example of how specific weather conditions can be conducive to extreme fire behavior. Analysis of the synoptic situation, together with examination of the available meteorological observations, allowed for characterizing these conditions. Furthermore, application of the coupled fire-atmosphere WRF-SFIRE modeling system allowed for successfully simulating fire spread, following the proper representation of the fuels available in the area, with particular emphasis given on the WUI. The following conclusions should contribute to the better organization and preparedness of civil protection agencies in Greece, an effort which today is among the top priorities of the state.

- A dense network of AWS over the area (especially near WUI) is of paramount importance for the continuous monitoring of the prevailing near-surface conditions. Continuous measurements of temperature, relative humidity, and wind, through a dense network of surface stations, can provide a real-time snapshot of the prevailing weather, which can be of great usefulness to fire managers before and during wildfires (Clements et al. 2007). The AWS network data can be also used for the calculation and operational provision of fire weather indices (such an example is given in http:// map.disarmfire.eu/Greece). 
- A rapid response fire spread forecasting system, such as WRF-SFIRE, could be exploited for providing forecast guidance of high added value.

- Field measurements during large wildfires are necessary for a better understanding of the fireatmosphere interactions, following recent good practices in the United States, such as described in Clements et al. (2018).

- The synergetic use of the aforementioned observational and modeling tools helps to assess the conditions that contribute to extreme fire behavior that often causes devastating impacts on the local population and provides the necessary basis for the validation of coupled fire-atmosphere models.

In conclusion, the disastrous wildfire of Attica set the stage for the overall redesign of strategies for fire danger warning and mitigation, a redesign which is of paramount importance in the context of increased frequency of high fire danger conditions expected under a changing climate.

ACKNOWLEDGMENTS. This research has been financed by the "Drought and Fire Observatory and Early Warning System (DISARM) INTERREG BALKANMEDITERRANEAN (2014-2020) project, which is cofunded by the European Union and national funds of the participating countries. The availability of the Global Forecasting System (GFS) and Global Data Assimilation System (GDAS) data is also greatly acknowledged.

\section{FOR FURTHER READING}

Abatzoglou, J. T., R. Barbero, and N. J. Nauslar, 2013: Diagnosing Santa Ana winds in Southern California with synoptic-scale analysis. Wea. Forecasting, 28, 704-710, https://doi.org/10.1175/WAF-D-13-00002.1.

Clements, C. B., and Coauthors, 2007: Observing the dynamics of wildland grass fires: FireFlux-A field validation experiment. Bull. Amer. Meteor. Soc., 88, 1369-1382, https://doi.org/10.1175/BAMS-88-9-1369.

— N. P. Lareau, D. E. Kingsmill, C. L. Bowers, C. P. Camacho, R. Bagley, and B. Davis, 2018: The Rapid Deployments to Wildfires Experiment (RaDFIRE): Observations from the Fire Zone. Bull. Amer. Meteor. Soc., 99, 2539-2559, https://doi.org/10.1175/BAMS-D-17-0230.1.

Diakakis, M., G. Xathopoulos, and L. Gregos, 2016: Analysis of forest fire fatalities in Greece: 1977-2013. Int. J. Wildland Fire, 25, 797-809, https://doi.org/10 .1071/WF15198.
Dimitrakopoulos, A. P., 2002: Mediterranean fuel models and fire behavior in Greece. Int. J. Wildland Fire, 11, 127-130, https://doi.org/10.1071/WF02018. Huang, C., Y. L. Lin, M. L. Kaplan, and J. J. Charney, 2009: Synoptic and mesoscale environments conducive to forest fires during the October 2003 extreme fire event in Southern California. J. Appl. Meteor. Climatol., 48, 553-579, https://doi.org /10.1175/2008JAMC1818.1.

Kalabokidis, K., P. Palaiologou, and M. Finnery, 2013: Fire behavior simulation in Mediterranean forests using the minimum travel time algorithm. Proc. Fourth Fire Behavior and Fuels Conference, Raleigh, NC, International Association of Wildland Fire, 468-492, www.iawfonline.org/wp -content/uploads/2018/02/4th_Fuels_Conference _Proceedings_USA-Russia_updated_5.28.2015.pdf.

Kotroni, V., K. Lagouvardos, and D. Lalas, 2001: The effect of Crete island on the Etesian winds over the Aegean Sea. Quart. J. Roy. Meteor. Soc., 127, 1917-1938, https://doi.org/10.1002/qj.49712757604.

Lagouvardos, K., and Coauthors, 2017: The automatic weather stations NOANN network of the National Observatory of Athens: Operation and database. Geosci. Data J., 4, 4-16, https://doi.org/10.1002/gdj3.44.

Lekkas, E., and Coauthors, 2018: The July 2018 Attica (central Greece) wildfires-Scientific report (version 1.0). Newsletter of Environmental, Disaster, and Crisis Management Strategies, No. 8, National and Kapodistrian University of Athens, Athens, Greece. Mandel, J., J. D. Beezley, J. L. Coen, and M. Kim, 2009: Data assimilation for wildland fires. IEEE Control Syst. Mag., 29, 47-65, https://doi.org/10.1109 /MCS.2009.932224.

- - - - and A. K. Kochanski, 2011: Coupled atmosphere-wildland fire modeling with WRF 3.3 and SFIRE 2011. Geosci. Model Dev., 4, 591-610, https:// doi.org/10.5194/gmd-4-591-2011.

— , and Coauthors, 2014: Recent advances and applications of WRF-SFIRE. Nat. Hazards Earth Syst. Sci., 14, 2829-2845, https://doi.org/10.5194/nhess -14-2829-2014.

Mass, C. F., and D. Ovens, 2019: The Northern California wildfires of 8-9 October 2017: The role of a major downslope wind event. Bull. Amer. Meteor. Soc., 100, 235-256, https://doi.org/10.1175/BAMS-D-18-0037.1.

Mills, G. A., and L. McCaw, 2010: Atmospheric stability environments and fire weather in Australia - Extending the Haines index. CAWCR Tech. Rep. 20, 158 pp., www.cawcr.gov.au/technical-reports /CTR_020.pdf. 
Nauslar, N., J. Abatzoglou, and P. Marsh, 2018: The 2017 North Bay and Southern California fires: A case study. Fire, 1, 18, https://doi.org/10.3390 /fire1010018.

Rothermel, R. C., 1972: A Mathematical Model for Predicting Fire Spread in Wildland Fires, USDA Forest Service Research Paper INT-115, 40 pp., www .treesearch.fs.fed.us/pubs/32533.

Ruffault, J., V. Moron, R. M. Trigo, and T. Curt, 2017: Daily synoptic conditions associated with large fire occurrence in Mediterranean France: Evidence for a wind-driven fire regime. Int. J. Climatol., 37, 524-533, https://doi.org/10.1002/joc.4680.

Salis, M., and Coauthors, 2016: Predicting wildfire spread and behavior in Mediterranean landscapes. Int. J. Wildland Fire, 25, 1015-1032, https://doi .org/10.1071/WF15081.
Scott, J. H., and R. Burgan, 2005: Standard fire behavior fuel models: A comprehensive set for use with Rothermel's surface fire spread model. USDA Forest Service General Tech. Rep. RMRS-GTR-153, 72 pp., www.fs.usda.gov/treesearch/pubs/9521.

Skamarock, W. C., and Coauthors, 2008: A description of the Advanced Research WRF version 3. NCAR Tech. Note NCAR/TN-475+STR, 113 pp., https://doi .org/10.5065/D68S4MVH.

Werth, P. A., and Coauthors, 2016: Synthesis of knowledge of extreme fire behavior: Volume 2 for fire behavior specialists, researchers, and meteorologists. USDA Forest Service General Tech. Rep. PNW-GTR-891, 258 pp., www.fs.usda.gov/treesearch/pubs/50530.

Whiteman, C. D., 2000: Mountain Meteorology: Fundamentals and Applications. Oxford University Press, 355 pp.

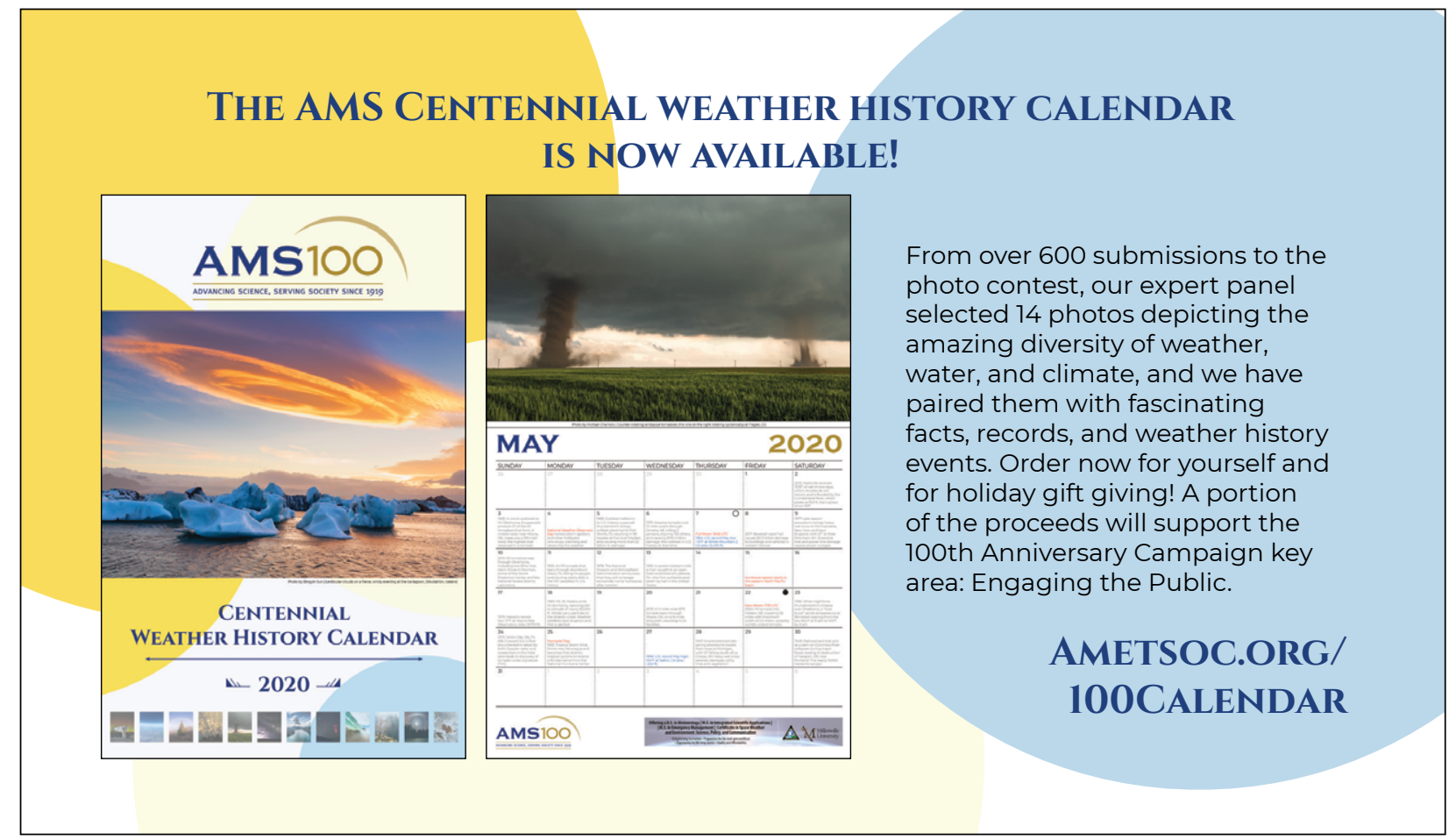


